\title{
Social purpose in an organization from the perspective of an employee: a self-determination outlook on the meaning of work
}

\author{
Malwina Puchalska-Kamińska', Agnieszka Łądka-Barańska² and Marta Roczniewska ${ }^{3,4^{*}}$ (1)
}

\begin{abstract}
Objective: Advancing social purpose in organizations is usually studied from the macro perspective, i.e., how it benefits organizational business goals or society more broadly. In this paper, we focus on social purpose from the perspective of the employee and propose that advancing social purpose in an organization allows individuals to fulfil an important human need for the meaning of work (MW). This study's objective was to assess whether a volunteering Corporate Social Responsibility (CSR) program in a manufacturing company allows employees to fulfil their basic psychological needs for relatedness, competence, and autonomy. The data was collected through in-depth interviews with 15 employees and an analysis of artifacts.
\end{abstract}

Results: In the analysis, three main themes describing different aspects of voluntary work at the company were identified. We found that across all groups of interviewed employees the voluntary activities served the needs of (1) relatedness, (2) competence, and (3) autonomy. We conclude that CSR programs have the most positive impact on MW when they allow employees to engage in prosocial actions and satisfy those needs.

Keywords: Corporate social responsibility, Meaning of work, Self-determination theory, Autonomy, Competence, Relatedness, Case study, Employee volunteering

\section{Introduction}

Recent research demonstrates that finding the meaning of work (MW) is a growing need among employees [1]. MW is the subjective experience of significance and intrinsic value in one's work [2]. Definitions of MW highlight an individual's need to make sense of one's self [3], find a sense of purpose in work $[4,5]$, and the desire to serve the greater good [6]. Based on Bakan's [7] framework of two fundamental modalities of human existence

\footnotetext{
*Correspondence: marta.roczniewska@ki.se

${ }^{3}$ Procome Research Group, Medical Management Center, Department of Learning, Informatics, Management and Ethics, Karolinska Institutet, Stockholm, Sweden

Full list of author information is available at the end of the article
}

(agency and communion), two aspects of MW can be derived [8]. Agentic $M W$ relates to perceiving one's work as meaningful to the extent to which the work brings personal benefits: enhances the meaning of one's life, contributes to a sense of self-development, and allows to accomplish goals central to the self [8]. Communal $M W$ refers to the degree to which an employee perceives the work as having a beneficial impact on other people or 'world' in general: it involves viewing one's work as a calling, a sense of fulfilling a mission at work, and acting for the good of the humanity or the environment [8].

Corporate social responsibility (CSR) programs, designed to serve a greater good, seem to have a potential to support the need for MW among employees, 
especially in its communal aspect. The problem is that many of the CSR initiatives are ill-suited to fulfil this need because they are often planned top-down, precluding employees from directly engaging in prosocial activities. This 'distance' can impede creation of communal MW for individual employees. In fact, research shows that most employees have little knowledge about their firm's CSR activities, and increasing employees' proximity to the CSR initiatives is seen as a major challenge for managers [9]. Yet, only active involvement in CSR activities relates to the meaning of work [10]. Following self-determination theory (SDT) [11, 12], we argue that prosocial actions in an organization create individual MW when they involve intrinsic (i.e., inherent drive) rather than extrinsic (i.e., external regulation) motivation.

The basic psychological needs for relatedness, competence, and autonomy are the basis of intrinsic motivation and behavior [13]. Relatedness reflects the extent to which a person feels that he or she "belongs", i.e., is connected to other people. This need is fulfilled when individuals are able to interact with others, experience caring for them [14], and have a sense of relevance in their lives [15]. CSR activities that are focused on helping others are inherently interpersonal. Relatedness is also developed by setting common goals, which builds a sense of cohesiveness in a team. Competence represents a sense of efficacy: the notion of being able to achieve one's goals [13]. To satisfy this need one ought to feel effective, i.e., perform a behavior that has a positive effect on the world [13]. Competence is related to the sense of mastery: an experience of being good at what one does [13]. Autonomy signifies undertaking decisions and actions with a sense of volition and internal locus of control. An autonomous act is considered to be an expression of one's values and reflects the self. To fulfil the need for autonomy, the actions need to be experienced as self-initiated, self-chosen, or self-endorsed. Thus, extrinsic awards or othersimposed conditions hamper intrinsic motivation [16].

Fulfilment of relatedness, competence, and autonomy needs is linked with positive employee outcomes [17]. Additionally, enhancement in well-being from prosocial behavior is mediated by the satisfaction of autonomy, competence and relatedness [18]. It follows, therefore, that CSR activities may be instrumental in creating communal MW as long as they serve the basic needs enlisted by SDT. In this article, we study a case of a manufacturing company whose business goals are not devoted to social purpose, like teaching, curing or helping. Thus, communal MW cannot be simply achieved by the employees by means of pursuing a job with a clear calling. Here, we focus on one of the company's core CSR activities, i.e., volunteer work, to answer a question whether it allows employees to fulfil the basic needs outlined by SDT.

\section{Main text \\ Materials and methods \\ Organizational context}

The study was conducted in a manufacturing company in Poland, which currently employs over 80 people (c. 50\% white collar employees). Voluntary work in this company is a part of their CSR. Each employee engages a minimum of 16 working hours in voluntary actions per year. There is a list of voluntary projects from which employees can choose activities, and they can submit new projects. Additionally, $1.5 \%$ of each employee's remuneration is allocated to the charity budget.

\section{Data collection and methods}

The study used qualitative research method. The data was collected through in-depth interviews and an analysis of artifacts, i.e., multimedia materials like employer branding ads and lectures where managers share knowledge about leadership. Semi-structured interviews with 15 employees from different departments were conducted: five blue-collar employees, five white-collar employees, and five managers. The interview guide contained questions about the characteristics of work, employee attitudes, and voluntary activities of employees (see Additional file 1). The interviews lasted 45 to $90 \mathrm{~min}$, were recorded, and transcribed verbatim.

Based upon SDT, three categories of codes were derived: relatedness, competence, and autonomy. Two team members (MPK, AŁB) independently reviewed the interviews and assigned the codes. Discrepancies were discussed and final decisions made by the whole team.

\section{Results}

In the analysis, three main themes related to SDT theory were derived. They described how voluntary activities served the needs of relatedness, competence, and autonomy. The themes are illustrated with quotes that are poignant and representative of the findings (see Table 1). The results are discussed for the three groups jointly (i.e., managers [M1-M6], white collar employees [WC1WC6], blue collar employees [BC1-BC6]), but we also point to differences in their experiences and perceptions.

\section{Relatedness}

One of the most distinctive characteristics of this volunteering program is the focus on local environment and personal contact. An example of this is an annual action of preparing Christmas gifts for the families in need who come from the city where the company is based. All employees are involved in this project. They form teams 


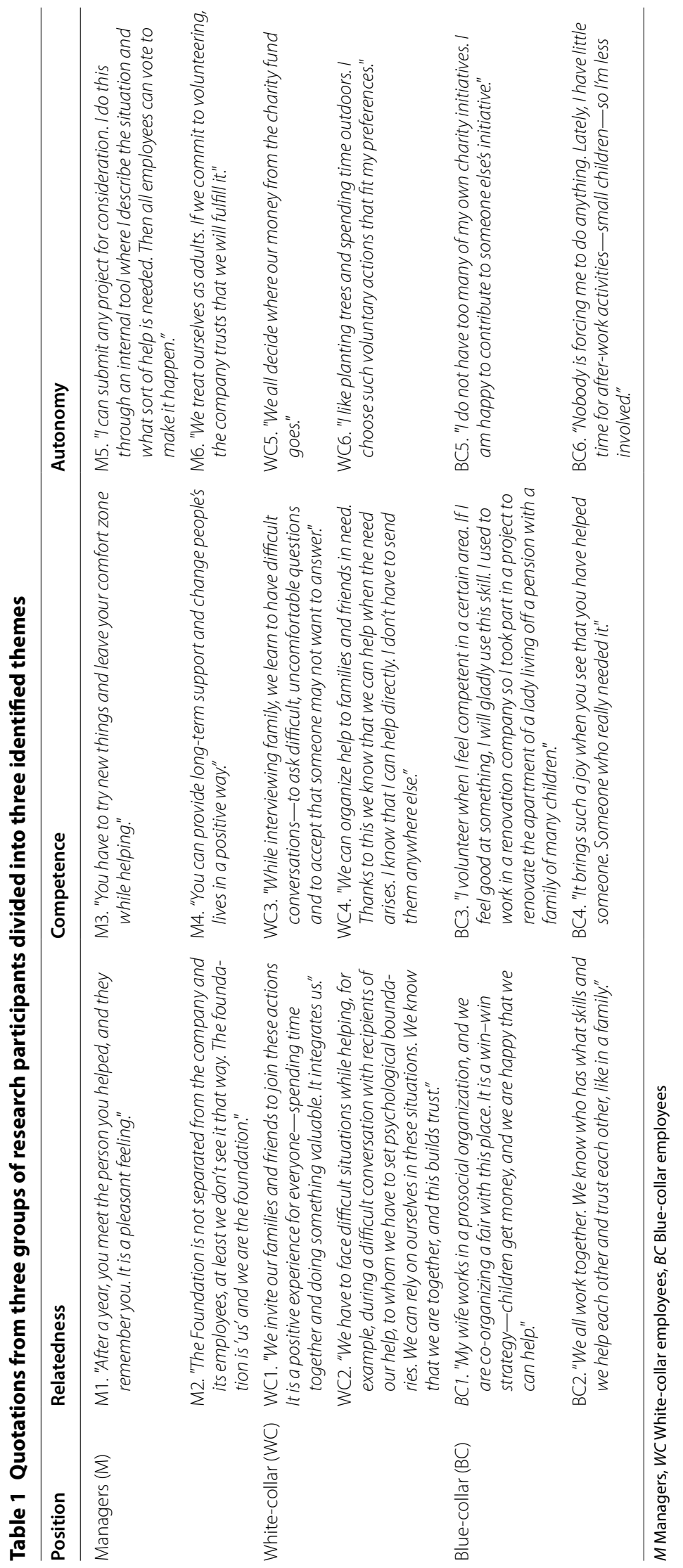


representing different departments and are responsible for finding a family that needs help. The gifts are delivered in person. These activities allow employees to create bonds with the help recipients (M1). As employees often invite their families to help, they feel that they are building a larger community of people who care for others. Spending time together with colleagues' relatives is considered a bonding experience (WC1, BC1).

Although projects are conducted in small teams, employees celebrate and exchange their experiences at the organizational level, e.g., during Christmas party, employees describe their Christmas gift project and show pictures/videos of the experience. Respondents expressed that helping under the auspices of their organization allows them to create a sense of mutual goals and values with other team members. Some of them declared that volunteering and dealing with potentially difficult situations together builds trust towards their coworkers (WC2). They often used metaphors of "a family" or "a sports team" when describing their organizational community (M2, BC2). They viewed the work at the company and their charity work as coherent, and they identified with both of them.

\section{Competence}

The fact that employees can freely choose a voluntary activity rather than being assigned to one, gives them an opportunity to utilize their strengths. Blue-collar workers focused mostly on being able to utilize their sills-they declared that they help in a way that is possible for them and that involves their skills and knowledge (BC3). Thus, they perceived their input from the perspective of being 'useful'. Managers and white-collar workers, one the other hand, saw the wide variety of possible voluntary activities as a chance to develop their competences or learn new things (M3, WC3). For example, helping others in need allowed them to develop necessary skills to deal with difficult emotions or situations.

As the projects are focused on solving concrete problems and are well-planed, respondents deemed observing the short- and long-term effects of their efforts as rewarding (M4). Being personally engaged in helping enables them to perceive the positive consequences of their actions (BC4) and enhance agency (WC4), which can further build self-efficacy.

\section{Autonomy}

Having a choice was one of the most important characteristics of volunteering expressed by respondents. Employees highlighted that they feel free to choose which voluntary action to engage in, and they described themselves as agents of decisions and actions. Managers and white-collar employees more often declared that they use a possibility to launch new projects (M5, WC5), while blue collar employees appreciated the opportunity to join others' initiatives (BC5). The freedom also enabled employees to act in accordance with their values and interests (WC6).

Respondents stated that when it comes to volunteering, they do not feel controlled. There are no official schedules or implemented ways to monitor employee volunteering activities by the management (M6) and they can engage to a varying extent given the circumstances (BC6). Importantly, there are no rewards for voluntary work. Employees treat it as part of their job rather than something unusual.

\section{Discussion}

In this case study, we showed that CSR activities can be construed so as to allow employees to create social bonds, to use strengths and build competence, as well as to be experienced as self-chosen and coherent with the self. Positive outcomes of helping for meaningfulness occur through the satisfaction of autonomy, competence and relatedness $[18,19]$. MW, being an 'abstract' concept, may be hard to put into practice [19]. Our findings point to concrete organizational practices that are supportive of autonomy, competence, and relatedness, and give managers more executable suggestions on how to support employees' MW.

The interviews uncovered that helping was perceived as an important aspect of employees' identification to the company, allowing them to create shared organizational identity. This finding points to possible additional benefits of satisfying relatedness, competence, and autonomy needs in CSR actions. For instance, social identification has been linked with positive health outcomes [20] and lower turnover intentions [21]. Additionally, shared experiences and a possibility to discuss them allows employees to create 'shared reality', which increases interpersonal connectedness and trust [22, 23]. Purposeful recruitment which considers person-organization fit as it relates to congruence in values that relate to benevolence can facilitate this process [24].

While acting for the 'greater good' serves the communal MW fulfilment [8], respondents in our interviews pointed to additional personal benefits of voluntary work, such as competence development or increasing the meaning life. Thus, we contribute to the literature by showing that CSR activities may be instrumental in shaping both the agentic and communal MW. The design of the presented CSR initiative can serve the full MW identified by Lips-Wiersma [25] as a combination of developing and becoming self, expressing full potential, unity with others, and serving others. 
To the best of our knowledge, this is the first case study which analyses the practical use of SDT in CSR solutions. Notably, SDT is a well-established framework and can provide evidence-based guidelines to design human resource management practices [11], including CSR solutions that support MW at work. Another strength of this case is its universality, since presented solutions are not industry-specific and can be adapted in different organizational contexts.

\section{Conclusions}

Implementing SDT theory in organizational CSR programs can serve as an evidence-based method of enhancing social purpose in organization and employees' MW. SDT initiatives should involve building connections, utilizing people's strengths, as well as allowing for autonomy. By engaging workforces in volunteering that follows these principles, companies may not only build its positive image but also enable employees to experience their organization as positive, which is an important factor of well-being at work [26].

\section{Limitations}

Some limitations need to be addressed. First, the interviews were drawn from one company in the private sector, which limits our ability to generalize the findings to the public sector [27]. Specifically, possibilities for empowerment may be limited in the latter context. Second, we only interviewed 15 employees; however, they represented distinct hierarchical levels (managers vs. non-managers) as well as position types (blue vs. white collar).

\section{Supplementary Information}

The online version contains supplementary material available at https://doi. org/10.1186/s13104-020-05432-4.

Additional file 1. Interview guide for the study.

\section{Abbreviations}

MW: Meaning of work; CSR: Corporate social responsibility; SDT: Self-determination theory.

\section{Acknowledgements}

Not applicable.

\section{Authors' contributions}

Conceptualization: MPK, AŁB, MR. Acquisition of data: AŁB. Analysis: MPK, AŁB. Writing - original draft preparation: MPK, AŁB, MR. Writing — review and editing: MR. Supervision: MR. All authors read and approved the final manuscript.

\section{Funding}

Open Access funding provided by Karolinska Institute.

\section{Availability of data and materials}

The data used and/or analysed during the current study are available from the corresponding author on reasonable request.

\section{Ethics approval and consent to participate}

The study described in this manuscript was carried out in accordance with the recommendations of the Ethics Committee for Research Projects of the Institute of Psychology at the University of Gdansk who provided specific approval for this research project after the research was reviewed (43/2020). All subjects provided written informed consents.

\section{Consent to publish}

Not applicable.

\section{Competing interests}

The authors declare that they have no competing interests.

\section{Author details}

${ }^{1}$ Institute of Psychology, SWPS University of Social Sciences and Humanities, Warsaw, Poland. ${ }^{2}$ Institute of Psychology, University of Gdansk, Gdansk, Poland. ${ }^{3}$ Procome Research Group, Medical Management Center, Department of Learning, Informatics, Management and Ethics, Karolinska Institutet, Stockholm, Sweden. ${ }^{4}$ Center of Research On Cognition and Behaviour, Institute of Psychology, Faculty in Sopot, SWPS University of Social Sciences and Humanities, Sopot, Poland.

Received: 16 October 2020 Accepted: 24 December 2020

Published online: 07 January 2021

\section{References}

1. Gallup Inc. State of the workplace. 2017. https://www.gallup.com/workp lace/238085/state-american-workplace-report-2017.aspx. Accessed 12 May.

2. Rosso BD, Dekas KH, Wrzesniewski A. On the meaning of work: a theoretical integration and review. Res Organ Behav. 2010;30:91-127. https://doi. org/10.1016/j.riob.2010.09.001.

3. Shamir B. Meaning, self and motivation in organizations. Organ Stud. 1991;12(3):405-24. https://doi.org/10.1177/017084069101200304.

4. Haslam SA, Powell C, Turner J. Social identity, self-categorization, and work motivation: rethinking the contribution of the group to positive and sustainable organisational outcomes. Appl Psychol. 2000;49(3):319-39. https://doi.org/10.1111/1464-0597.00018.

5. Sparks JR, Schenk JA. Explaining the effects of transformational leadership: an investigation of the effects of higher-order motives in multilevel marketing organizations. J Organ Behav. 2001;22(8):849-69. https://doi. org/10.1002/job.116.

6. Wrzesniewski A, McCauley C, Rozin P, Schwartz B. Jobs, careers, and callings: people's relations to their work. J Res Pers. 1997;31(1):21-33. https:// doi.org/10.1006/jrpe.1997.2162.

7. Bakan D. The duality of human existence: isolation and communion in Western man. Chicago: Rand McNally; 1966.

8. Puchalska-Kamińska M, Czerw A, Roczniewska M. Work meaning in self and world perspective: a new outlook on the WAMI scale. Soc Psychol Bull. 2019;14(1):1-29. https://doi.org/10.32872/spb.v14i1.30207.

9. Bhattacharya CB, Sen S, Korschun D. Using corporate social responsibility to win the war for talent. MIT Sloan Manag Rev. 2008;49(2):37-44. https:// sloanreview.mit.edu/article/using-corporate-social-responsibility-to-winthe-war-for-talent/.

10. Supanti D, Butcher K. Is corporate social responsibility (CSR) participation the pathway to foster meaningful work and helping behavior for millennials? Int J Hosp Manag. 2019;77:8-18. https://doi.org/10.1016/j. ijhm.2018.06.001.

11. Rigby CS, Ryan RM. Self-determination theory in human resource development: new directions and practical considerations. Adv Dev Hum Resour. 2018;20(2):133-47. https://doi.org/10.1177/1523422318756954.

12. Ryan RM, Deci EL. Self-determination theory and the facilitation of intrinsic motivation, social development, and well-being. Am Psychol. 2000;55(1):68-78. https://doi.org/10.1037//0003-066x.55.1.68.

13. Ryan RM, Deci EL. Overview of self-determination theory: an organismicdialectical perspective. In: Ryan RM, Deci EL, editors. Handbook of self-determination research. New York: The University of Rochester Press; 2002. p. 3-33. 
14. Baumeister RF, Leary MR. The need to belong: desire for interpersonal attachments as a fundamental human motivation. Psychol Bull. 1995;117(3):497-529. https://doi.org/10.1037/0033-2909.117.3.497.

15. Rosenberg M, McCullough BC. Mattering: inferred significance and mental health among adolescents. Res community Ment Health. 1981;2:163182. https://psycnet.apa.org/record/1983-07744-001.

16. Deci EL. Effects of externally mediated rewards on intrinsic motivation. J Pers Soc Psychol. 1971;18(1):105-15. https://doi.org/10.1037/h0030644.

17. Van den Broeck A, Ferris DL, Chang C-H, Rosen CC. A review of selfdetermination theory's basic psychological needs at work. J Manage. 2016;42(5):1195-229. https://doi.org/10.1177/0149206316632058.

18. Weinstein N, Ryan RM. When helping helps: autonomous motivation for prosocial behavior and its influence on well-being for the helper and recipient. J Pers Soc Psychol. 2010;98(2):222-44.

19. Martela F, Riekki TJJ. Autonomy, competence, relatedness, and beneficence: a multicultural comparison of the four pathways to meaningful work. Front Psychol. 2018. https://doi.org/10.3389/fpsyg.2018.01157.

20. Steffens NK, Haslam SA, Schuh SC, Jetten J, van Dick R. A Meta-analytic review of social identification and health in organizational contexts. Pers Soc Psychol Rev. 2017;21(4):303-35. https://doi.org/10.1177/1088868316 656701.

21. Van Dick R, Wagner U, Stellmacher J, Christ O, Tissington PA. To be(long) or not to be(long): social identification in organizational contexts. Genet Soc Gen Psychol Monogr. 2005;131(3):189-218. https://doi.org/10.3200/ MONO.131.3.189-218.
22. Rossignac-Milon M, Bolger N, Zee KS, Boothby EJ, Higgins ET. Merged minds: generalized shared reality in dyadic relationships. J Pers Soc Psychol. 2020. https://doi.org/10.1037/pspi0000266.

23. Higgins ET. Shared reality: what makes us strong and tears us apart. New York: Oxford University Press; 2019.

24. Andersson O, Huysentruyt M, Miettinen T, Stephan U. Person-organization fit and incentives: a causal test. Manage Sci. 2017;63(1):73-96. https://doi. org/10.1287/mnsc.2015.2331.

25. Lips-Wiersma M. The influence of spiritual "meaning-making" on career behavior. J Manag Dev. 2002;21(7):497-520. https://doi. org/10.1108/02621710210434638.

26. Czerw A. Diagnosing well-being in work context-eudemonic wellbeing in the workplace questionnaire. Curr Psychol. 2017;38:1-16. https:// doi.org/10.1007/s12144-017-9614-8.

27. Wynen J, Verhoest K, Rübecksen K. Decentralization in public sector organizations: do organizational autonomy and result control lead to decentralization toward lower hierarchical levels? Public Perform Manag Rev. 2014;37(3):496-520. https://doi.org/10.2753/PMR1530-9576370307.

\section{Publisher's Note}

Springer Nature remains neutral with regard to jurisdictional claims in published maps and institutional affiliations.
Ready to submit your research? Choose BMC and benefit from:

- fast, convenient online submission

- thorough peer review by experienced researchers in your field

- rapid publication on acceptance

- support for research data, including large and complex data types

- gold Open Access which fosters wider collaboration and increased citations

- maximum visibility for your research: over 100M website views per year

At BMC, research is always in progress.

Learn more biomedcentral.com/submissions 